\title{
Exploring Gender Differences in Academic Motivation among Adolescents
}

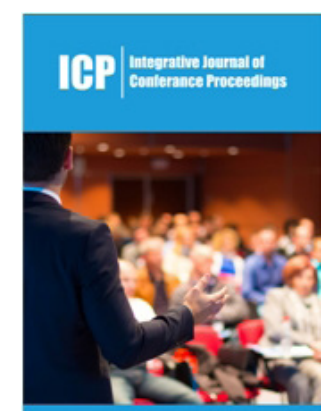

*Corresponding author: Muhammad Kamran Chaudhry, International Islamic University, Islamabad, Pakistan

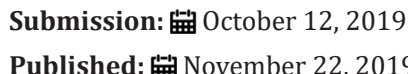

Volume 2 - Issue 1

How to cite this article: Chaudhry M, Shabbir F. Exploring Gender Differences in Academic Motivation among Adolescents. Int J Conf Proc.2(1). ICP.000527.2019.

Copyright@ Muhammad Kamran Chaudhry, This article is distributed under the terms of the Creative Commons Attribution 4.0 International License, which permits unrestricted use and redistribution provided that the original author and source are credited.

\author{
Chaudhry MK* and Shabbir F \\ International Islamic University, Pakistan
}

\begin{abstract}
The purpose of present study was to find the relationship between dimensions of Academic Motivation including Intrinsic Motivation, Extrinsic Motivation and A-motivation among adolescents as well as investigated the gender differences present among adolescents related to Academic Motivation. Convenient sampling was used for the selection of the research sample. The sample of this study consisted of $(\mathrm{N}=160)$ college students. The age of participants ranged from 16-20 years. Informed consent was taken from the participants before filling the questionnaires. The research protocols were administered to the participants along with verbal instructions. They included demographic sheet and Academic Motivation Scale (college version). The data from this method was tabulated to conclude the results of the research using SPSS software. Reliability analysis, Correlation, $t$ test and manova were used to test hypotheses of the study. Data was statistically analyzed by statistical package for social sciences (SPSS23 V). The results show that Intrinsic Motivation and Extrinsic Motivation are positively correlated with each other whereas A-motivation is negatively correlated with Intrinsic Motivation as well as with Extrinsic Motivation. Results further indicated that male adolescents have significantly low rates of Intrinsic Motivation as compared to female adolescents. Similarly, male adolescents are lower in Extrinsic Motivation as compared to female adolescents. Whereas male adolescents rate higher in A-motivation as compared to female adolescents. The results concluded that interaction among gender and education of the sample was significant on intrinsic motivation and extrinsic motivation. When Gender and level of education are interacted, they significantly influence the rates of intrinsic motivation and extrinsic motivation.
\end{abstract}

Key words: Gender differences; Academic motivation; Adolescents

\section{Introduction}

Academic motivation is the corner stone for success in college students. Student's success is highly dependent on level of motivation they hold. College time endows with the foundation to enter the professional education. Some college students are more motivated to learn than others, hence need arises to explore the reasons. Academic motivation is a student's desire regarding academic subjects when the student's competence is judged against a standard of performance or excellence. Psychologists noted that motivation should be taken into account in education because of its effective relationship with new learning, abilities, strategies and behaviors and they have presented motivation for academic achievement as one of the preliminary constructs for defining such type of motivation [1].

\section{Self-Determination Theory}

Self-determination theory is an approach that focuses on self-determined or autonomous and controlled behaviors. Self-determination theory suggests that a person who is unmotivated feels no ambition and excitement towards accomplishing a task. According to the self-determination continuum, self-determination has diverse theories such as intrinsic motivation, extrinsic motivation and a-motivation [2].

\section{Intrinsic motivation}

Intrinsic motivation is the self-desire to attempt or do new things and new challenges. In this a person does a certain task because they enjoy doing it or have an interest in doing it, they don't rely on external pressure or a desire for reward [3]. For example: A person becomes a musician because he or she wants to learn how to play different instruments. That person has the intrinsic motivation to learn how to play an instrument. 


\section{Extrinsic motivation}

According to [3] extrinsic motivation refers to the performance of an activity in order to achieve a desired outcome and it is the opposite of intrinsic motivation. It is behavior that is done to get a reward such as money, grades, and praise. This type of motivation arises from outside the individual rather than the inside. For example: A child does a certain chore to gain reward from his/her parents.

\section{Amotivation}

A state of lacking any motivation to engage in an activity because an individual lacks the ability to do a task or does not value the activity or task itself. The individual will display neither intrinsic nor extrinsic behavior [3]. For example, an Amotivated athlete will not know why they participate in their sports. In addition, they won't find any benefits from participation in the sports or physical activity.

\section{Method}

\section{Problem statement}

The present study aimed to find gender differences in Academic Motivation among adolescents as well as to explore interaction effects of gender and education with academic motivation among adolescents.

\section{Objectives}

1. To find out the relationship between Intrinsic Motivation, Extrinsic Motivation and A-motivation among adolescents.

2. To investigate differences in Academic Motivation across gender among adolescents.

3. To explore interaction effect of gender and education with Academic Motivation among adolescents.

\section{Hypotheses}

Following hypotheses are formulated to achieve the objectives of the study;

1. There will be significant relationship between Intrinsic Motivation, Extrinsic Motivation and A-motivation among adolescents.

2. Male and female adolescents will be different in levels of Academic Motivation.

3. There will be significant interaction among gender and education with Academic Motivation.

\section{Sample}

The sample of this study consisted of $(\mathrm{N}=160)$ college students. Participants in this study included 80 females and 80 males, who were selected from different colleges. The age of participants ranged from 16-20 years. Convenient sampling was used for the selection of the research sample.

\section{Procedure}

Data was collected from different colleges of Rawalpindi. First of all, Permission was taken from principle in colleges, and then the questionnaires were filled by participants after taking consent from students. Participants were briefed about the nature of study and they were also assured that the information provided by them would be kept confidential and will be used only for the research purpose. Informed consent was taken from the participants before filling the questionnaires. The research protocols were administered to the participants along with verbal instructions. They included demographic sheet and Academic Motivation Scale (college version).

\section{Demographic sheet}

Demographic sheet was formulated to access the name of the participant, age, gender, current class and family system.

\section{Instrument}

Academic motivations scale college version (AMS): Academic Motivations Scale [4] was used to access participant's academic motivation. Academic Motivations Scale is deeply rooted in self-determination theory, the AMS consists of 28 items measured on a 7-point Likert scale (ranging from 1=does not correspond at all to $7=$ corresponds exactly). The AMS measures the participants' perceptions of academic motivation based on three subscales of Intrinsic Motivation (12 items), Extrinsic Motivation (12 items), and A-motivation ( 4 items). The scale was highly reliable $(\alpha=.92)$ and for its subscales it ranged from $\alpha=.92$ to $\alpha=.71$

\section{Operational definition}

Academic motivation: "Student's desire regarding academic subjects when the student's competence is judged against a standard of performance or excellence [1]. The index of academic motivation will be scores obtained from intrinsic motivation, extrinsic motivation and a-motivation [4].

\section{Results}

Present study examined the relationship between dimensions of Academic Motivation including Intrinsic Motivation, Extrinsic Motivation and A-motivation among adolescents as well as investigated the gender differences present among adolescents related to Academic Motivation. To measure academic motivation among adolescents, Academic Motivation Scale (AMS-college version) was used. Reliability analysis, Correlation, $t$ test and manova were used to test hypotheses of the study. Data was statistically analyzed by statistical package for social sciences (SPSS23 V). Table 1 demonstrates demographic variables of the sample including age, family system and education. It also indicates that, the maximum age of students is 17 and the minimum age is 21 . The highest percentage of females falls under the age of 17 whereas the highest percentage of males falls under the age of 16 . As for the family system, about $40 \%$ of the adolescents belong to joint family system and about $60 \%$ of the adolescents belong to nuclear family system. In the domain of education, first year and second year students have equal proportion. 
Table 1: Distribution of demographic variables $(\mathrm{N}=160)$.

\begin{tabular}{|c|c|c|c|}
\hline Variables & Male (\%) & Female (\%) & Total (\%) \\
\hline \multicolumn{4}{|c|}{ Age } \\
\hline 16 & $14(56)$ & $11(44)$ & $25(15.62)$ \\
\hline 17 & $24(41.3)$ & $34(58.6)$ & $58(36.25)$ \\
\hline 18 & $24(57.1)$ & $18(42.8)$ & $42(26.25)$ \\
\hline 19 & $11(47.8)$ & $12(52.17)$ & $23(14.37)$ \\
\hline 20 & $3(37.5)$ & $5(62.5)$ & $8(5)$ \\
\hline 21 & $4(100)$ & 0 & $4(2.5)$ \\
\hline \multicolumn{4}{|c|}{ Family System } \\
\hline Joint & $43(68.2)$ & $20(48.2)$ & $63(39.4)$ \\
\hline Nuclear & $37(38.1)$ & $60(61.8)$ & $97(60.6)$ \\
\hline \multicolumn{4}{|c|}{ Education } \\
\hline First year & $44(55)$ & $36(45)$ & $80(50)$ \\
\hline Second year & $36(45)$ & $44(55)$ & $80(50)$ \\
\hline
\end{tabular}

First year students have more number of males as compared to females where as in second year there is a larger population of female students. Table 2 indicates the Cronbach's alpha reliability of Academic Motivation scale and it's all subscales. It shows that Academic Motivation Scale has high reliability $(\alpha=0.82)$. All subscales including Intrinsic Motivation $(\alpha=0.82)$, Extrinsic Motivation $(\alpha=0.82)$ and Amotivation $(\alpha=0.82)$ are also highly reliable and the data gathered by these instruments is reliable for data analysis. Table 3 indicates correlation coefficients for subscales of academic motivation scale. The results show that Intrinsic Motivation and Extrinsic Motivation are positively correlated $(\alpha=.59 * *, p<.001)$ with each other whereas A-motivation is negatively correlated with Intrinsic Motivation $\left(\alpha=-.32^{* *}, \mathrm{p}<.001\right)$ as well as with Extrinsic Motivation $\left(\alpha=-.48^{* *}, \mathrm{p}<.001\right)$. Table 4 showed the results of t-test for comparing mean differences on the basis of gender on Intrinsic Motivation (IM), Extrinsic Motivation (EM), and A-motivation (AM). Thus, indicating that male adolescents $(M=55.7, S D=10)$ have significantly low rates of Intrinsic Motivation as compared to female adolescents $(\mathrm{M}=60.7, \mathrm{SD}=12.1)$.
Table 2: Psychometric properties of Academic Motivation Scale $(\mathrm{N}=160)$.

\begin{tabular}{|c|c|c|c|c|c|c|}
\hline Variable & $\mathbf{K}$ & $\mathbf{M}$ & $\mathbf{S . ~ D}$ & $\mathbf{a}$ & $\begin{array}{c}\text { Skew- } \\
\text { ness }\end{array}$ & S. E \\
\hline $\begin{array}{c}\text { Academic moti- } \\
\text { vation }\end{array}$ & 28 & 131.4 & 21.5 & 0.82 & 0.19 & 1.71 \\
\hline $\begin{array}{c}\text { Intrinsic Motiva- } \\
\text { tion }\end{array}$ & 12 & 58.22 & 11.36 & 0.75 & -0.04 & 0.89 \\
\hline $\begin{array}{c}\text { Extrinsic Moti- } \\
\text { vation }\end{array}$ & 12 & 60.14 & 12.29 & 0.75 & -0.14 & 0.97 \\
\hline Amotivation & 4 & 12.98 & 5.44 & 0.59 & -0.03 & 0.43 \\
\hline
\end{tabular}

Similarly, male adolescents $(M=56.3, S D=10.6)$ are lower in Extrinsic Motivation as compared to female adolescents $(M=63.9$, $\mathrm{SD}=12.7)$. Whereas in A-motivation, male adolescents $(\mathrm{M}=15.4$, $\mathrm{SD}=4.5)$ rate higher as compared to female adolescents $(\mathrm{M}=10.4$, $\mathrm{SD}=5.1$ ). MANOVA for gender and education on academic motivation- Intrinsic Motivation, Extrinsic Motivation and Amotivation was done. The results in Table 5 concluded that interaction among gender and education of the sample was significant on intrinsic motivation and extrinsic motivation. Gender and level of education when combined, significantly influence the rates of intrinsic motivation (MS=149.74, $\mathrm{p}<.05$ ) and extrinsic motivation (MS=56.78, $\mathrm{p}<.05$ ). Figure 1 shows the interaction effect of gender and education on intrinsic motivation. Intrinsic motivation is strongly influenced by gender and education. Males of first year have more intrinsic motivation than females of first year. Whereas, males of second year scored lower in intrinsic motivation than females of same year. Figure 2 showed the interaction effect of gender and education on extrinsic motivation. Gender and level of education strongly influence extrinsic motivation. Males of first year have lower extrinsic motivation as compared to females of first year. Whereas, males of second year are higher in extrinsic motivation than females of second year.

Table 3: Correlation matrix for subscales of Academic Motivation $(\mathrm{N}=160), \mathrm{p}=<0.01$.

\begin{tabular}{|c|c|c|c|}
\hline Variables & $\mathbf{1}$ & $\mathbf{2}$ & $\mathbf{3}$ \\
\hline Intrinsic motivation & 1 & $.59^{* *}$ & $-.32^{* *}$ \\
\hline Extrinsic motivation & - & 1 & $-.48^{* *}$ \\
\hline Amotivation & - & - & 1 \\
\hline
\end{tabular}

Table 4: Mean, Standard Deviation and t-values of Academic Motivation between Males ( $\mathrm{n}=80)$ and Females ( $\mathrm{n}=80$ ).

\begin{tabular}{|c|c|c|c|c|c|c|c|c|c|c|}
\hline \multirow[b]{3}{*}{ Scales } & \multirow{2}{*}{\multicolumn{2}{|c|}{$\begin{array}{l}\text { Males } \\
\mathbf{n}=\mathbf{8 0}\end{array}$}} & \multirow{2}{*}{\multicolumn{2}{|c|}{$\begin{array}{c}\text { Females } \\
\mathbf{n}=\mathbf{8 0}\end{array}$}} & \multirow{2}{*}{\multicolumn{6}{|c|}{$95 \% \mathrm{CI}$}} \\
\hline & & & & & & & & & & \\
\hline & $\mathbf{M}$ & SD & $\mathbf{M}$ & SD & $\mathbf{T}$ & Df & $\mathbf{P}$ & LL & UL & Cohen's d \\
\hline IM & 55.7 & 10 & 60.7 & 12.1 & 2.8 & 158 & 0 & -8.4 & -1.4 & 0.4 \\
\hline $\mathrm{AM}$ & 15.4 & 4.5 & 10.4 & 5.1 & 6.5 & 158 & 0 & 3.4 & 6.5 & 1 \\
\hline EM & 56.3 & 10.6 & 63.9 & 12.7 & 4 & 158 & 0 & -11.2 & -3.8 & 0.6 \\
\hline
\end{tabular}

Note: $\mathrm{IM}=$ Intrinsic Motivation, EM=Extrinsic Motivation, AM=A-motivation 
Table 5: Manova for gender and education on Intrinsic motivation, Extrinsic motivation and A-motivation (N=160).

\begin{tabular}{|c|c|c|c|c|c|c|}
\hline \multirow{2}{*}{ Source } & Dependent Variable & SS & Df & MS & F & 伍 \\
\hline \multirow{3}{*}{ Gender*edu } & Intrinsic & 598.97 & 4 & 149.74 & $1.40^{*}$ & 0.04 \\
\cline { 2 - 7 } & Extrinsic & 227.15 & 4 & 56.78 & $.49^{* * *}$ & 0.01 \\
\cline { 2 - 7 } & Amotivation & 79.271 & 4 & 19.818 & 0.82 & 0.02 \\
\hline
\end{tabular}

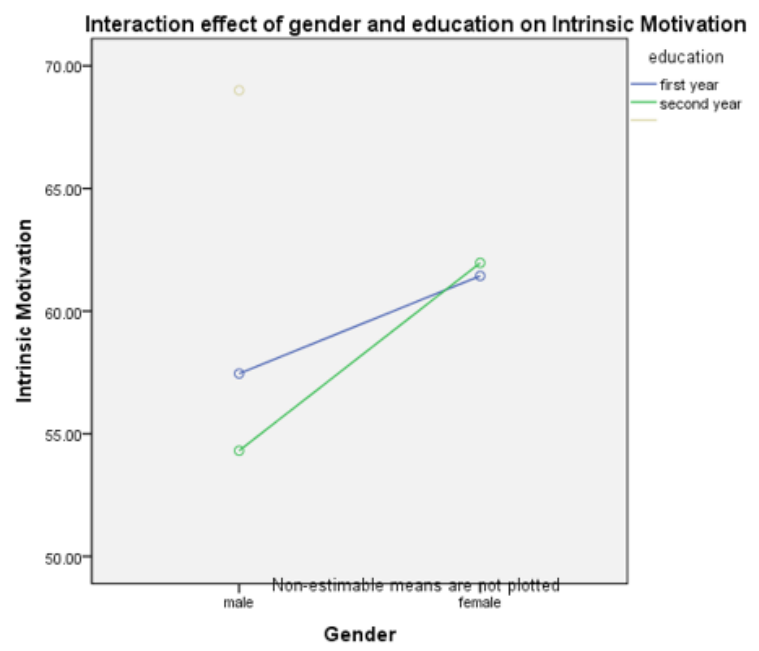

Figure 1: Graph showing Interaction among gender and education and their impact on intrinsic motivation.

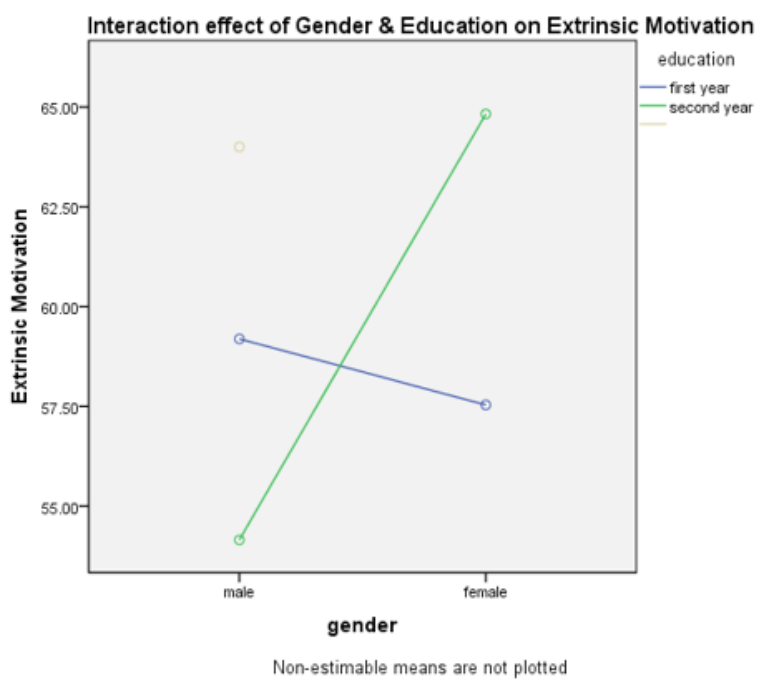

Figure 2: Graph showing Interaction among gender and education and their impact on extrinsic motivation.

\section{Discussion}

Present study examined the relationship between dimensions of Academic Motivation including Intrinsic Motivation, Extrinsic Motivation and A-motivation among adolescents as well as investigated the gender differences present among adolescents related to Academic Motivation. Academic motivation is the corner stone for success in college students. Student's triumph is highly dependent on level of motivation they hold. College time endows with the foundation to enter the professional education. Some college stu- dents are more motivated to learn than others, hence need arises to explore the reasons. Academic motivation is a student's desire regarding academic subjects when the student's competence is judged against a standard of performance or excellence. Psychologists noted that motivation should be taken into account in education because of its effective relationship with new learning, abilities, strategies and behaviors and they have presented motivation for academic achievement as one of the preliminary constructs for defining such type of motivation [1]. 
Table 1 demonstrates demographic variables of the sample including age, family system and education. It also indicates that, the maximum age of students is 17 and the minimum age is 21 . The highest percentage of females falls under the age of 17 whereas the highest percentage of males falls under the age of 16 . As for the family system, about $40 \%$ of the adolescents belong to joint family system and about $60 \%$ of the adolescents belong to nuclear family system. In the domain of education, first year and second year students have equal proportion. First year students have more number of males as compared to females where as in second year there is a larger population of female students.

Table 2 indicates the Cronbach's alpha reliability of Academic Motivation scale and it's all subscales. It shows that Academic Motivation Scale has high reliability ( $\alpha=0.82$ ). All subscales including Intrinsic Motivation $(\alpha=0.82)$, Extrinsic Motivation $(\alpha=0.82)$ and Amotivation $(\alpha=0.82)$ are also highly reliable and the data gathered by these instruments is reliable for data analysis. The first hypothesis proposed that there will be significant relationship between Intrinsic Motivation, Extrinsic Motivation and A-motivation among adolescents. Table 3 indicates correlation coefficients for subscales of academic motivation scale. The results show that Intrinsic Motivation and Extrinsic Motivation are positively correlated $\left(\alpha=.59^{* *}, \mathrm{p}<.001\right)$ with each other whereas A-motivation is negatively correlated with Intrinsic Motivation $(\alpha=-.32 * *, p<.001)$ as well as with Extrinsic Motivation $\left(\alpha=-.48^{* *}, \mathrm{p}<.001\right)$. These findings are in line with previous research finding which indicated that a significant positive relationship exists between intrinsic motivation and extrinsic motivation [5]. The aim of the study [5] was to explore relationship between intrinsic and extrinsic motivation on academic performance. A sample of 200 students (100 males and 100 females) was selected from different colleges of Karachi. The age of the participants ranged from 18-21 years (with mean age of 18.56 years). Their educational level was at least intermediate and socioeconomic status was middle and high class. Results suggested that intrinsic and extrinsic motivation and academic performance were positively correlated $(r=.563 ; n=200$; sig=.000). Second hypothesis profess that male and female adolescents will be different in levels of Academic Motivation. Table 4 showed the results of t-test for comparing mean differences on the basis of gender on Intrinsic Motivation (IM), Extrinsic Motivation (EM), and A-motivation (AM). Thus, indicating that male adolescents $(M=55.7, S D=10)$ have significantly low rates of Intrinsic Motivation as compared to female adolescents $(M=60.7, S D=12.1)$. Similarly, male adolescents $(\mathrm{M}=56.3, \mathrm{SD}=10.6)$ are lower in Extrinsic Motivation as compared to female adolescents $(M=63.9, S D=12.7)$. Whereas in A-motivation, male adolescents $(\mathrm{M}=15.4, \mathrm{SD}=4.5)$ rate higher as compared to female adolescents $(\mathrm{M}=10.4, \mathrm{SD}=5.1)$.

In a previous research done in Karachi Pakistan, gender difference was found $(\mathrm{t}=4.324, \mathrm{p}<.05)$ on motivation and academic performance. To conclude, findings of the results illustrates that there is gender difference in motivation type and academic performance [5]. Female college students were more motivated as compared to males; the same hypothesis was proved in a previous research [6]. The results of our study are consistent with the previous research that says that female respondents are more motivated in studies
[7]. According to our study males are more amotivated as compared to females towards their study, which is consistent with many previous research findings $[8,9]$. Prior research has also shown consistent results regarding the differences of lack of motivation as stated in the study which investigated gender differences in adolescents' academic motivation and classroom behavior and gender differences in the extent to which motivation was associated with, and predicted, classroom behavior.

Seven hundred and fifty students (384 boys and 366 girls) aged between eleven and sixteen completed a questionnaire examining academic motivation and teachers completed assessments of their classroom behavior. The results stated that girls generally reported higher levels of academic motivation, whilst boys were poorer in academic motivation, having high rates of lack of motivation [10]. Third hypothesis suggested that there will be significant interaction among gender and education with Academic Motivation. MANOVA for gender and education on academic motivation- Intrinsic Motivation, Extrinsic Motivation and Amotivation was done. The results concluded that interaction among gender and education of the sample was significant on intrinsic motivation and extrinsic motivation. Gender and level of education when combined, significantly influence the rates of intrinsic motivation (MS=149.74, p<.05) and extrinsic motivation (MS=56.78, $\mathrm{p}<.05$ ). Figure 1 shows the interaction effect of gender and education on intrinsic motivation. Intrinsic motivation is strongly influenced by gender and education. Males of first year have more intrinsic motivation than females of first year. Whereas, males of second year scored lower in intrinsic motivation than females of same year.

Figure 2 showed the interaction effect of gender and education on extrinsic motivation. Gender and level of education strongly influence extrinsic motivation. Males of first year have lower extrinsic motivation as compared to females of first year. Whereas, males of second year are higher in extrinsic motivation than females of second year. Findings of the present study concluded that an interaction among gender and education with intrinsic motivation as well as with extrinsic motivation is present, that is consistent with previous research stating that a person's gender and his or her level of education strongly influence the rates of intrinsic motivation as well as extrinsic motivation [11].

\section{Conclusion}

Present study examined the relationship between dimensions of Academic Motivation including Intrinsic Motivation, Extrinsic Motivation and A-motivation among adolescents as well as investigated the gender differences present among adolescents related to Academic Motivation. The results show that Intrinsic Motivation and Extrinsic Motivation are positively correlated with each other whereas A-motivation is negatively correlated with Intrinsic Motivation as well as with Extrinsic Motivation. Results further indicated that male adolescents have significantly low rates of Intrinsic Motivation as compared to female adolescents. Similarly, male adolescents are lower in Extrinsic Motivation as compared to female adolescents. Whereas male adolescents rate higher in A-motivation as compared to female adolescents. The results concluded that interaction among gender and education of the sample was signifi- 
cant on intrinsic motivation and extrinsic motivation. When Gender and level of education are interacted, they significantly influence the rates of intrinsic motivation and extrinsic motivation.

\section{Implications, limitations and suggestions}

1. While present research relied more on quantitative and survey research, qualitative research may also be utilized to seek in-depth information on the topic through engaging faculty members and students in group discussions through focus group discussions and interviews.

2. Further this study can be conducted using large population as the sample of this study was small.

3. This study has offered some insights, guidelines and caveats for future research.

4. This study is an effective contribution to the understanding of the adaptation and integration of students as well as to study their wellbeing.

5. The sample taken in the study was taken only from private schools. For future studies, corporate evaluations among students of private higher education and public higher education can be conducted with a good sample size

Next studies should explore the reason behind the differences in extrinsic and intrinsic motivation among male and female as well as among first year students and second year students.

\section{References}

1. DiPerna JC, Elliott SN (1999) Development and validation of the academic competence evaluation scales. Journal of Psychoeducational Assessment 17(3): 207-225.
2. Deci EL, Koestner R, Ryan RM (2000) Extrinsic rewards and intrinsic motivation: Clear and reliable effects. University of Rochester, New York, USA.

3. Deci EL (2000) Effects of externally mediated rewards on intrinsic motivation. Journal of Personality and Social Psychology 18(1): 105-115.

4. Vallerand R, Pelletier L, Blais M, Brire NM, Senécal C, et al. (1992) The academic motivation scale: A measure of intrinsic, extrinsic, and amotivation in education. Educational and Psychological Measurement 52(4): 1003-1017.

5. Nadia A (2010) Effect of intrinsic and extrinsic motivation on academic performance. Pakistan Business Review 12: 363-372.

6. Narayanan R, Rajasekaran NN, Iyyappan S (2007) Do female students have higher motivation than male students in learning of English at the tertiary level? pp. 1-15.

7. Gardner RC, Lambert WE (1972) Attitudes and motivation in second language learning. Newbury House, USA.

8. Spolky B (1989) Conditions for second language learning. Oxford university press, UK.

9. Bacon S (1992) The relationship between gender, comprehension, processing strategies, and cognitive and affective response in second language learning. The Modern Language Journal 76(2): 160-178.

10. Bugler M, McGeown S, St Clair Thompson H (2013) Gender differences in adolescents' academic motivation and classroom behaviour. Educational Psychology 35(5): 541-556.

11. Chung L, Chang R (2017) The Effect of gender on motivation and student achievement in digital game-based learning: A case study of a contented-based classroom. Eurasia Journal of Mathematics, Science and Technology Education 13(6): 2309-2327. 